\title{
Endoscopic dacryocystorhinostomy: The outcome of 25 patients.
}

\author{
Basil M.N. Saeed *, Amer Y.Rajab *, Nazar N. Fadhil *, Ahlam A. Al-Ghani**, \\ *Department of Surgery, College of Medicine, University of Mosul ** Consultant eye surgeon, Al-Jamhori \\ Teaching Hospital, Mosul.
}

(Ann. Coll. Med. Mosul 2008; 34(2): 81-86).

Received:16 ${ }^{\text {th }}$ July 2008; Accepted: $5^{\text {th }}$ Nov 2008.

\begin{abstract}
Objective: To assess the outcome of endoscopic transnasal dacryocystorhinostomy (DCR) as a new approach in our center( Al-Jamhori Teaching Hospital) in treating 25 patients complaining of epiphora and recurrent or chronic dacryocystitis, comparing our results with the reviewed literature.

Patients and Methods: Twenty-five (25)patients, with age range(from 5-55 years), underwent endoscopic DCR in the period from March/2006- July/2007 in Al-Jamhori Teaching Hospital, Mosul. Standard procedure was implemented using the drill and inserting temporary stents. Patients were followed up for 6-24(average of 8.8) months to assess the outcome of surgery.

Results: There was improvement in symptoms in 18 patients with disappearance of epiphora with $72 \%$ success rate. One patient had orbital fat prolapse and 3 patients developed postoperative adhesions. No major complication, namely severe bleeding, CSF leak or serious orbital injury occurred. Revision surgery was done on 3 failed cases; only one patient had clinical improvement. The total success rate after revision surgeries is $76 \%$.

Conclusion: We conclude that endoscopic DCR, which is a new experience in Iraq, is a safe technique in treating nasolacrimal duct obstruction with an acceptable success rate that matches many studies.
\end{abstract}

الخلاصة

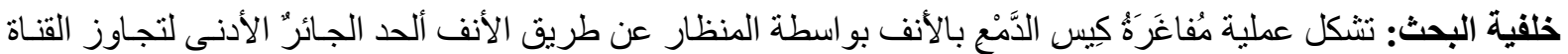

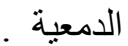

هدف الاراسـة: تقييم نتائج العمليـة كطريقة جديدة في مركزنـا( المستشفى الجمهوري التعليمسي) في عـلاج هب مريضـا

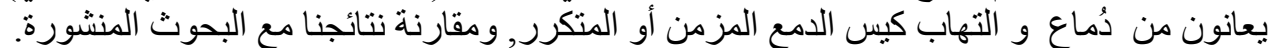

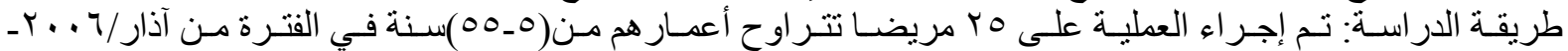

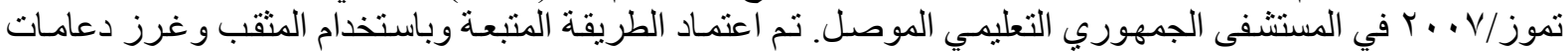

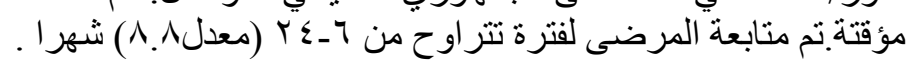

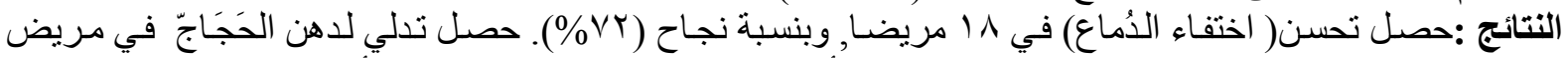

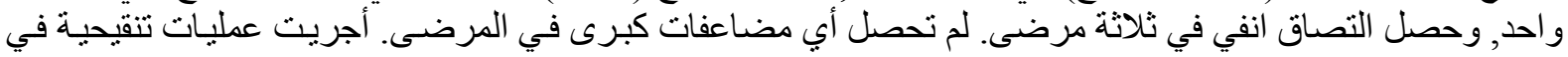

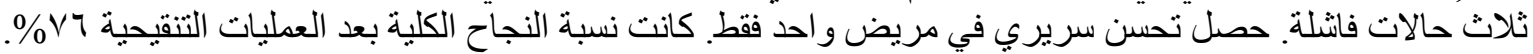

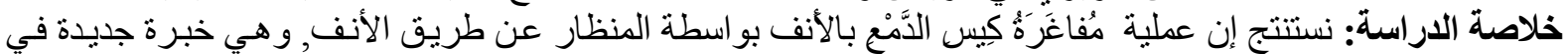

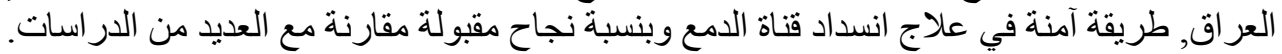

$\mathrm{D}$ acryocystorhinostomy (DCR) was first described via an external approach by Toti in1904 ${ }^{(1)}$. In 1989, McDonogh and Meiring described the endoscopic transnasal $\mathrm{DCR}^{(2)}$.
Endoscopic DCR is a minimally invasive procedure used to bypass the nasolacrimal duct. It is simply fistulization of the lacrimal sac into the nasal cavity. It is indicated when there 
is obstruction of the nasolacrimal duct with consequent dacryocystitis ${ }^{(3)}$.

Rice in 1990 reported his experience using endoscopes. The nasolacrimal duct and sac are readily accessible from the nasal cavity ${ }^{(4)}$. Endoscopic DCR has two significant advantages over the external approach: external cutaneous scarring can be avoided, and the medial canthal ligament is not disrupted, preserving the normal pumping functions of the nasolacrimal $\mathrm{sac}^{(5)}$. The endoscopic DCR surgical technique is not standardized in the literature ${ }^{(6)}$. It simply involves removal of the nasal mucosa; the creation of a bony opening at the level of the lacrimal bone using a bone rongeur,

power drill, or laser; and then stripping the lacrimal sac to create a direct fistula from the sac to the nose ${ }^{(7,8)}$. Possible complications of endoscopic DCR include excessive bleeding, orbital fat prolapse, orbital damage and even blindness ${ }^{(9)}$. The objective of this study is to assess the outcome (safety and effectiveness) of endoscopic DCR as a new approach adopted by the authors to treat nasolacrimal duct obstruction, and comparing the results of this approach in our center with others in the reviewed literature.

\section{Patients and methods:}

Twenty-five(25) patients were included in this study which was performed at Al-Jamhori Teaching Hospital, Mosul, in the period from March/2006-July/2007. The patients were complaining of epiphora and recurrent dacryocystitis and were fully assessed by their ophthalmologists. The age was ranging from(555 years), with a mean of (31.44) years. There were 17 female and 8 male patients. In the ENT department, they were further assessed by diagnostic nasal endoscopy. CT was done to 2 patients with nasal polyps that did not resolve with proper medical therapy (Fig.1).

\section{The operative procedures:}

The same ENT surgeon(B.M.N.S) performed all endoscopic procedures which were done under general anesthetic in combination with the ophthalmologist. Zero degree endoscope was used exclusively throughout the procedure.

The procedure included incision of the mucosa just anterior to the anterior end of the middle turbinate; the mucosal flap was elevated to expose the frontal process of the maxilla. An angled drill with a diamond bur was used to remove the bone and to expose the lacrimal sac, the ophthalmologist helped to identify the sac by probing it from the lower lacrimal canaliculus. The bony window was enlarged to expose the sac as much as possible. The inner part of the sac was first incised with a sickle knife and the medial portion excised. With the help of the ophthalmologist, the stent was inserted from both upper and lower canaliculi and knotted in the nose. Haemostasis was achieved by using patties soaked with 1:10000 adrenaline.

Removal of the unciform bone was needed in 12 patients for proper sac exposure. Two patients had additional endoscopic sinus surgery to treat co-existent sinus disease. Eight patients needed septoplasty done in the conventional method to get access to the lacrimal sac area. Figure 2 shows the steps of the operation in a patient who needed concomitant septoplasty. Table I shows the details of the DCR procedures. All patients were given antibiotics for 2 weeks. Patients were followed up weekly in the first month and monthly for at least 6 months. The stents were removed at the end of the third month postoperatively. Patients with nasal polyps were given steroid nasal sprays for 3 months. Endoscopic nasal examination with fluorescein dye applied into the conjunctiva was done at the time of stent removal.

\section{Results:}

Twenty-five(25) patients underwent endoscopic DCR for nasolacrimal duct obstruction and chronic dacryocystitis. Eight of them had septoplasty to correct obstructing septal deviation, and 2 (19 \& 42 year) female patients had endoscopic sinus surgery done at the same session to treat co-existent sinus disease. In one patient(24 year male), orbital fat prolapse occurred during the procedure, yet operation was completed with no serious postoperative complications. Postoperative adhesions occurred in 3 patients. No major complications, namely, severe hemorrhage, orbital injury, optic nerve injury or C.S.F. leak occurred. The follow up period was from 6-24 
months, (average 8.8 months), and the stents were removed at the end of the third month postoperatively. The primary success rate was $72 \%$. Eighteen(18) patients had clinical improvement with relief of epiphora and no further attacks of postoperative dacryocystitis. It was evidenced by endoscopic examination of the neo-ostium in the nose with fluorescein dye applied into the conjunctiva. The dye was seen exiting through the new ostium into the nose (Fig.3). Seven patients had little or no improvement of their complains. Of the failed cases, 2 patients were missed and 5 patients had further assessment. Table 2 summarizes the results and complications our patients. Two patients were found to have canalicular obstruction evidenced by normal nasal endoscopy of the neo-ostium and failure to irrigate the lower lacrimal canaliculus. Three patients with adhesions and granulations in the operative site underwent revision surgery with lysis of the adhesions and re-inserting of the stents. Nasal steroid drops ((betamethasone)) was prescribed to patients to prevent granulations. Only one patient had improvement after 3 months. Patients who failed the revision surgery were referred to the ophthalmologist for external DCR.

Table I. Demographics of endoscopic DCR patients

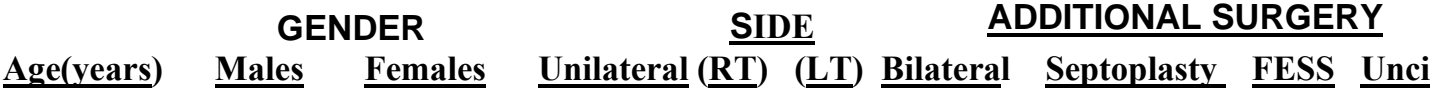

$\begin{array}{cccccccccc}1-10 & 0 & 1 & 1 & 0 & 1 & 0 & 0 & 0 & 0 \\ 11-20 & 3 & 3 & 6 & 5 & 1 & 0 & 2 & 1 & 2 \\ 21-30 & 2 & 1 & 3 & 1 & 2 & 0 & 0 & 0 & 1 \\ 31-40 & 2 & 7 & 9 & 2 & 7 & 0 & 3 & 0 & 6 \\ 41-50 & 1 & 3 & 3 & 0 & 3 & 1 & 3 & 1 & 2 \\ 51-60 & 0 & 2 & 2 & 2 & 0 & 0 & 0 & 0 & 1 \\ \text { Total No. } & 8 & 17 & 24 & 10 & 14 & 1 & 8 & 2 & 12\end{array}$

RT= Right; LT= Left; FESS= Functional Endoscopic Sinus Surgry; Unci= Uncinectomy.
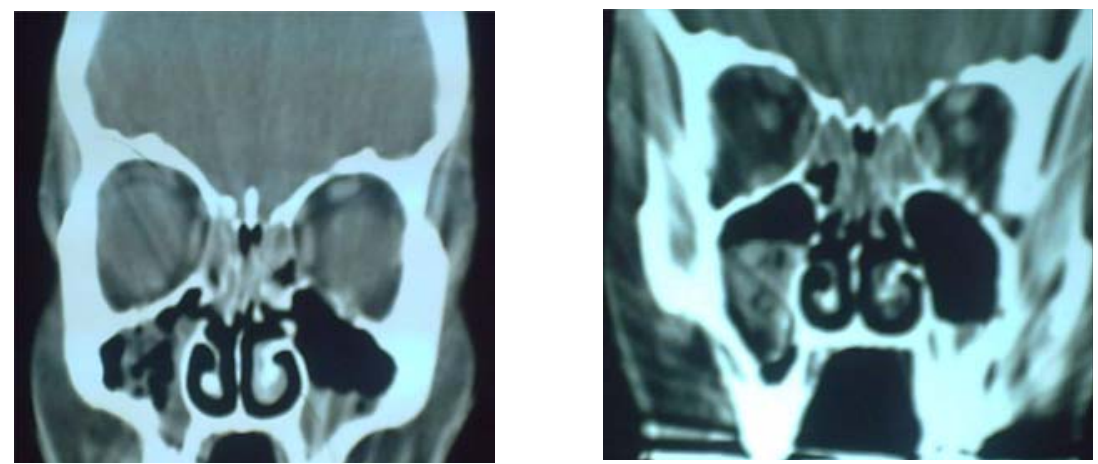

Figure1: CT scan of a patient with evidence of chronic rhinosinusitis and nasal polyposis. She underwent additional endoscopic sinus surgery 


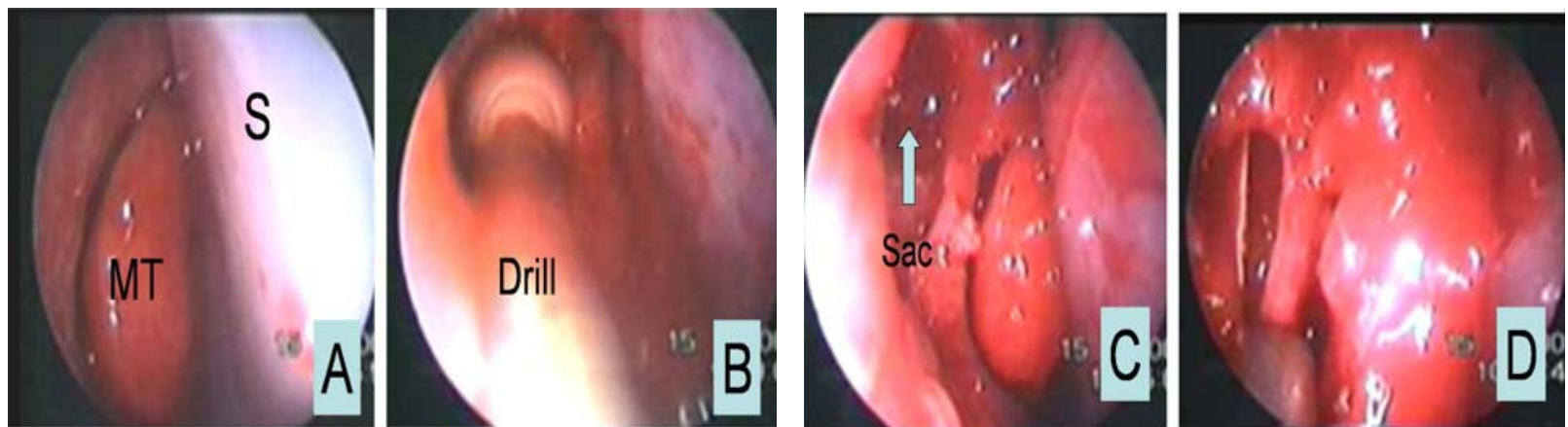

Figure 2: The steps of endoscopic DCR on the right side. See the silasic sheet (S) on the septum after septoplasty(A). Drilling of the area anterior to the middle turbinate MT (B). The sac is opened(C). Stents are inserted (D).

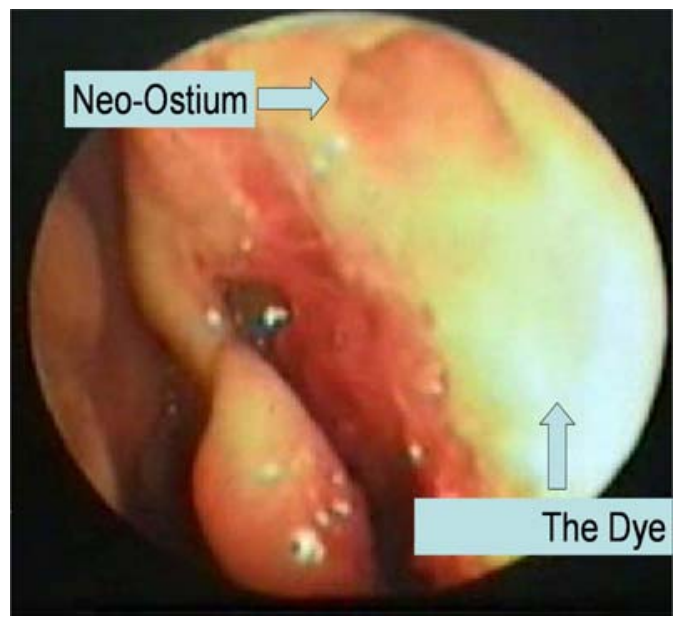

Figure 3: Endoscopic findings at the time of stent removal. The fluorescein dye applied to the coniunctiva exits into the nasal

Table 2: Complications and results of the endoscopic DCR

$\begin{array}{lllllr} & \text { Age(year) } & \text { Number } & \text { Complications } & \text { Success } & \text { Failure } \\ 1-10 & 1 & 0 & 1 & 0 \\ 11-20 & 6 & 1 \text { (Ad) } & 4 & 2 \\ 21-30 & 3 & 2(1: \text { OP) } & 1 & 2 \\ 31-40 & 9 & 1(\text { Ad) Ad) } & 7 & 2 \\ 41-50 & 4 & 0 & 3 & 1 \\ 51-60 & 2 & 0 & 2 & 0 \\ \text { Total No. } & 25 & 3 & 18 & 7\end{array}$




\section{Discussion:}

The advantages of the endoscopic approach in DCR are minor traumatization, preservation of lacrimal pump function, and reduction of surgical time. The success rate of endoscopic DCR is comparable to that of the traditional external procedure, with minimal morbidity and the possibility to treat simultaneous sinonasal diseases ${ }^{(3)}$.

It is not easy to compare the published success rates of lacrimal surgery because different studies use different criteria of success and varying patient selection. In 1999 the Royal College of Ophthalmologists published guideline; for clinical governance suggests that freedom from epiphora 3 months after surgery is the marker for a satisfactory procedure ${ }^{(10)}$.

In our patients, the success was determined by resolution of symptoms and anatomic patency assessed by fluorescein flow on nasal endoscopy. The primary success rate in our study is $72 \%$, and the follow up period was averaged 8.8 months ( from 6- 24 months). The success rate increased to $76 \%$ after revision surgeries.

Reported success rates of endoscopic DCR in several reviewed papers range from $79.4 \%$ to $96 \%,{ }^{(3,11-15)}$ while laser endoscopic DCR is successful between 58 and $85^{(15)}$. Success rates of $94 \%$ and $58 \%$ have been reported in two groups of patients that underwent endoscopic DCR, with expert and non-expert surgeons, respectively ${ }^{(3)}$.

If we compare the success rate of this study with the above mentioned reports, we see that the total success rate is $76 \%$. In the first 13 cases in this series we had success rate of $61.5 \%$ (8 out of 13 ), in the second 12 patients, we had only 2 failures making the success rate $83.3 \%$.These figures match many reviewed studies. When we first performed endoscopic DCR, it was still a new experience for the authors. The improved results in the second half of cases confirms the learning curve of the endoscopic procedure which was demonstrated in several studies, with higher success rates by more experienced surgeons $^{(12)}$
The endonasal approach often requires septal or turbinate surgery to optimize access to the lacrimal area. The incidence of concomitant procedures in a study was $21.5 \%$ of patients required additional endonasal procedures to improve access to the lacrimal area ${ }^{(16)}$. Another study showed that $35 \%$ of patients needed septoplasty, and 19\% had additional endoscopic sinus surgery ${ }^{(17)}$. In our study 8 patients(32\%) needed septal correction, and 2 patients(8\%) needed sinus surgery.

Complications of endoscopic DCR include re-stenosis of the opening, bleeding from the nasal cavity, orbital injury, CSF leak through a fractured ethmoid and corneal abrasion or erosion of canaliculi due to overly-tight silicone tube placement ${ }^{(9)}$. The only significant complication encountered in our patients was one case of orbital fat prolapse during surgery, which had no significant sequel. A similar case was noticed (one case of orbital fat exposure) in a study on 36 patients using powered drill ${ }^{(18)}$. The most common cause of a surgical failure in endoscopic DCR is obstruction of the neo-ostium by granulation tissue or synechia that forms postoperatively ${ }^{(8,12)}$. To avoid or prevent obstruction of the neo-ostium, some adopted the use of steroids or mitomycin- ${ }^{(19)}$. In our patients, we used topical steroid drops (betamethasone) in those in whom granulation tissue was evident on nasal endoscopy in an attempt to prevent or reduce recurrence. Although silicone stents are absolutely inert and usually harmless, on prolonged placement they can act as a nidus for granuloma formation and infection, leading to failure of the lacrimal procedure in the long run $^{(20)}$.

Removal of the stents before 3 months is considered a cause of failure, granulation tissue may be detected after 3 months of stenting ${ }^{(3)}$. We adopted removal of the stents at the end of the third month postoperatively.

\section{Conclusion:}

Endoscopic transnasal DCR is an effective and safe method in treating patients with nasolacrimal duct obstruction and chronic or 
recurrent dacryocystitis with rapid relief of symptoms. It is easy to learn and the results improve with increasing experience in this method. We recommend it as the first step in the management of symptomatic patients with nasolacrimal duct obstruction who failed to respond to medical treatment.

\section{References:}

1- Griffiths JD. Nasal catheter use in dacryocystorhinostomy. Ophthal Plast Reconstr Surg 1991; 7:177-86.

2- McDonogh $\mathrm{M}$, Meiring $\mathrm{JH}$. Endoscopic transnasal dacryocystorhinostomy. J Laryngol Otol 1989; 103: 585-7.

3- Muscatello L, Giudice M, Spriano G, Tondini L. Endoscopic dacryocystorhinostomy: personal experience. Acta Otorhinolaryngol Ital 2005; 25:209-213.

4- Rice DH. Endoscopic intranasal dacryocystorhinostomy results in four patients. Arch Otolaryngol Head Neck Surg 1990; 116:1061.

5- Sprekelsen MB, Barberan MT. Endoscopic dacryocystorhinostomy: surgical technique and results. Laryngoscope 1996; 106:187-9.

6- Eloy P, Bertrand B, Martinez M, Hoebeke M, Watelet JB, Jamart J. Endonasal dacryocystorhinostomy: indications, technique and results. Rhinology 1995; 33:229-33.

7- Yung MW, Hardman-Lea S. Endoscopic inferior dacryocystorhinostomy. Clin Otolaryngol 1998; 23: 152-7.

8- Massaro BM, Gonnering RS, Harris GJ. Endonasal laser dacryocystorhinostomy. A new approach to nasolacrimal duct obstruction. Arch Ophthalmol 1990; 108:1172-6.

9- Fayet B, Racy E, Assouline M. Complications of standardized endonasal dacryocystorhinostomy with unciformectomy. Ophthalmology 2004; 111: 837-45.

10- Yung MW, Hardman-Lea S. Analysis of the results of surgical endoscopic dacryocystorhinostomy: effect of the level of obstruction. Br J Ophthalmol 2002 ;86:7924.
11- Mantynem J, Yoshitsugu M, Rautiainen M. Results of dacryocystorhinostomy in 96 patients. Acta Otolaryngol Suppl (Stockh) 1997; 529:187-9.

12- Ben Simon GJ, Joseph J, Lee S, Schwarcz RM, McCann JD, Goldberg RA. External versus endoscopic dacryocystorhinostomy for acquired nasolacrimal duct obstruction in a tertiary referral center. Ophthalmology 2005;112:1463-8.

13- Cokkeser $\mathrm{Y}$, Evereklioglu $\mathrm{C}, \mathrm{Er} \mathrm{H}$. Comparative external versus endoscopic dacryocystorhinostomy: results in 115 patients (130 eyes). Otolaryngol Head Neck Surg 2000; 123: 488-91.

14- Dolman PJ. Comparison of external dacryocystorhinostomy with non laser endonasal dacryocystorhinostomy. Ophthalmology 2003; 110: 78-84.

15- Jin HR, Yeon JY, Choi MY. Endoscopic dacryocystorhinostomy: creation of a large marsupialized lacrimal sac. J Korean Med Sci 2006; 21:719-23.

16- Nussbaumer M, Schreiber S, Yung MW. Concomitant nasal procedures in endoscopic dacryocystorhinostomy: J Laryngol Otol. 2004;118:267-9.

17- Tsirbas A, Davis G, Wormald PJ. Mechanical endonasal dacryocystorhinostomy versus external dacryocystorhinostomy. Ophthal Plast Reconstr Surg 2004;20:50-6.

18- Wormald PJ. Powered endoscopic dacryocystorhinostomy. Laryngoscope 2002 ;112:69-72.

19- Selig YK, Biesman BS, Rebeiz EE. Topical application of mitomycin-C in endoscopic dacryocystorhinostomy. Am J Rhinol 2000; 14: 205-7.

20- Bajaj MS, Pushker N, Balasubramanya R, Rani A. Surgical endoscopic dacryocystorhinostomy. British Journal of Ophthalmology 2002;86:1460. 